\title{
Conservation systems: Benefits in managing drought and mitigating yield loss by improving soil quality
}

Mahdi Al-Kaisi, professor and Extension soil and water specialist, Agronomy, lowa State University; David Kwaw-Mensah, research associate, Agronomy, lowa State University; Jose Guzman, graduate research assistant, Agronomy, lowa State University.

\section{Introduction}

Soil conservation is essential to sustain soil quality and improve crop productivity. Soil quality indicators include improved water infiltration and storage, and adequate levels of available soil nutrients for plants and soil carbon. Droughts result from a deficiency of precipitation from statistically normal amounts that when extended makes precipitation inadequate to meet the demands for crop production. Therefore, agriculture is the first economic sector that is visibly impacted by drought because of lack of soil moisture, which affects soil nutrient cycling and crop productivity. The recent drought in Iowa has presented such challenges to corn and soybean production across Iowa. According to the US Drought Monitor report for October, Iowa is 100\% abnormally dry with $2.5 \%$ of the Northwestern corner of the State under exceptionally drought conditions and 63\% of lowa is under extreme drought conditions (Rippey, 2012). With the current weather challenges, conservation planning is becoming increasingly necessary, as Iowa experiences this extreme weather conditions and their impacts on crop production and soil quality. The USDA National Agricultural Statistics Service is forecasting significant corn and soybean yield losses in Iowa. Expected average bushels of corn grain for Iowa as of October 1, 2012, is 140 bu/acre, (32 bu/acre less than in 2011). Soybean yields are expected to fall by 8 bu/acre compared to the average yield of 51 bu/acre in 2011.

Consequently, Iowa farmers are being urged to avoid soil tillage to retain soil moisture and reduce erosion as dry conditions persist. Soil erosion is always associated with tillage intensity in many parts of the State during the spring when land is most vulnerable to water erosion due to lack of vegetation cover or residue to protect the soil surface from the intensity of rain. Many factors contribute to this problem, but tillage is the prime contributing factor. Many producers have voluntarily adopted conservation practices that lessen the negative impacts of agricultural activities on the environment. The outcome has been significant over the past few decades, with benefits in increased crop productivity, more efficient use of time and equipment, and a reduction in soil erosion. However, the current soil erosion level stands at approximately 5 tons/acre, and in some areas of the State this figure can be exceeded by 10 fold or more. This presents a challenge to examine and sustain our effort of implementing and targeting conservation practices in the most sensitive areas of the State to minimize the impact of soil erosion on soil and water quality. The current commodity prices, coupled with the promotion of tillage technology, presents a significant challenge for producers to adopt a system's approach to conservation practices as an integrated practice of conservation can be very powerful for high economic returns with excellent environmental rewards.

Soil management practices that protect soil quality are not only economically and environmentally necessary, but constitute the right conservation ethic to land stewardship. Therefore, producers should consider adopting conservation plans that are practical, site specific, and integrate them into the overall production system to achieve intended objectives. These conservation plans would include reduced tillage such as no-till and strip-tillage, which leave post-harvest crop residue to cover the soil surface. The following are a number of soil conservation plans producers can consider in this extreme drought conditions: the use of cover crops, the construction of grass waterways, terraces, buffer strips and pasture erosion control systems with manure application and soil testing plans .Conservation planning and implementation need to be carefully considered as solutions to reduce potentially negative impacts of row cropping system on soil and water quality. Consideration of site specifics and the objectives of implementation should be included in the planning process. Finally, the systems approach to conservation must include nutrient loading and sediment reduction plans as effective measures to protect soil and water quality. 


\section{Discussion}

\section{Drought effects on corn yields in Iowa}

Drought conditions in 2012 significantly reduced corn yields across Iowa with variable severity by region (Fig.1). In the Northcenral (glacial till, poorly-draining soils) and Southwest (loess, well-draining soils) regions, corn yields were reduced compared to 2011 without any significant differences between tillage management. This result might be due to these soils' excellent water storage capacity at lower depths, which reduced the effects of drought across tillage systems. Persistent drought might deplete this subsoil stored water leading to yield reductions, especially in tilled soils. In the Southcentral region (high clay content, poorly-draining soils), corn yields in 2012 were greater in no-till and strip-till than in tilled soils; CP,DR and MP in 2012, compared with corn yields for NT and ST in 2011, where there was adequate rainfall. Typically, Iowa has adequate rainfall that is essential for good yield. However, when soil moisture is a limiting factor as in 2012, reducing tillage intensity such as strip-tillage or notill can increase water storage, thus reducing the effects of drought on corn yield. In Northcentral Iowa, corn yield reductions for tillage systems due to drought conditions in 2012from 2011 are as follow: 60 bu/acre (DR), 80 bu/ acre (CP), 80 bu/acre (ST), and 70 bu/acre for NT. Meanwhile, in Southwest Iowa, corn yield reductions are as follow: 58 bu/acre with CP, 66 bu/acre with ST, 73 bu/acre with NT, 72 bu/acre with MP, and 70 bu/acre with DR. Contrary to these findings, corn yields in Southcentral Iowa in 2012 are better than in 2011 by 30 bu/acre with NT and 5 bu/acre with ST while CP, DR and MP yields experienced yield reductions as much as 70, 50, and 75 bu/acre, respectively.

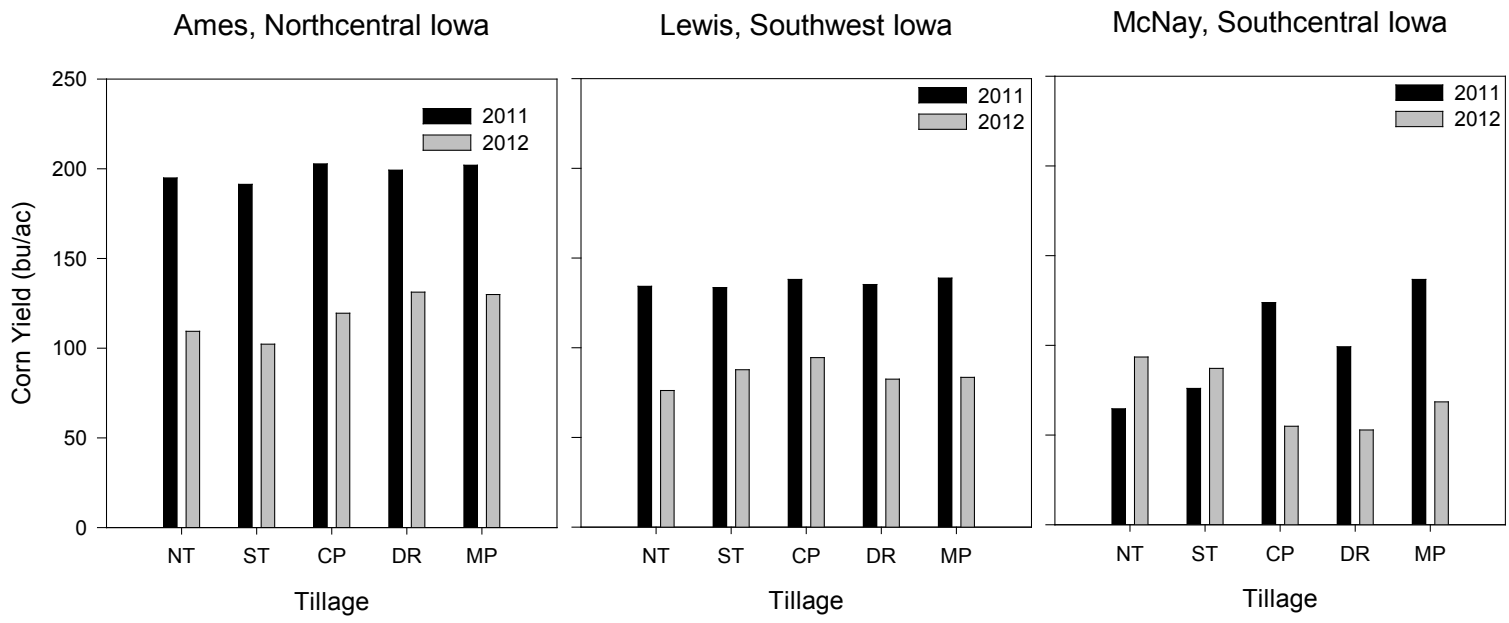

Figure 1. Tillage effects on corn yield in 2011 and 2012 by region. NT=no-till; $S T=$ strip-tillage; $C P=$ chisel plow; $\mathrm{DR}=$ deep rip; $\mathrm{MP}=$ moldboard plow.

\section{Tillage management under drought conditions}

The current drought challenges require proactive planning with the introduction of some management aspects that may not be appealing to many. However, to reduce the potential damage and mitigate some of the impacts of drought on the next growing season, certain management practices need to be considered. The early harvest this fall and the extended period of time before the next growing season can be tempting for farmers to do more tillage. Tillage will not minimize or improve the impact of drought on the soil structure. On the contrary, soil tillage at the current dry soil condition will destroy soil structure and any rain will destroy soil aggregates, seal the soil surface of freshly tilled soils and result in significant soil erosion and loss of residual nutrients not utilized by the crop. Additionally, tillage in this dry condition will compromise any chance to recharge the subsoil, a condition that is desperately needed to make up for water loss during dry conditions.

Studies have shown that agricultural management practices can significantly influence soil hydraulic properties and processes in space and time (Dao, 1993; Green et al., 2003; Kennedy and Schillinger, 2006; Celik and Ersahin, 2011).Conservations tillage systems such as no-till increase water infiltration (Fig.2). In combination with high organic matter content, no-till soils increase soil water storage (Fig.3). Typically, no-till surface soils (0-8 in) have 
greater water content at planting than plowed and stubble mulch tilled soils (Dao, 1993). This is attributed to differences in surface residue cover as tilling prior to planting increases evaporation losses. Studies in many parts of the country and elsewhere show that full width tillage is not the best solution for improving productivity, soil quality, energy use, labor, and time. Many conservation systems can work as good as full width tillage such as striptillage, where tilled zone of 8 inches wide and 6 inches deep is done. This system is very efficient and effective in nutrient placement, where tillage and nutrients application are coupled in a single operation.

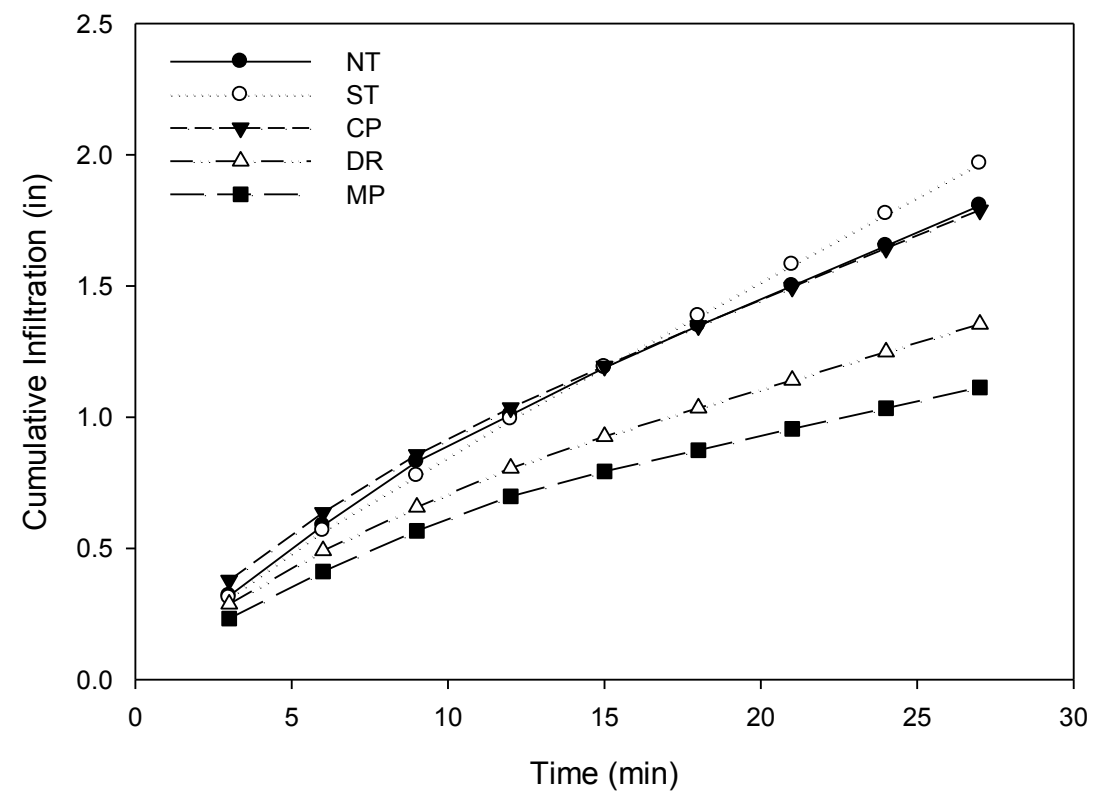

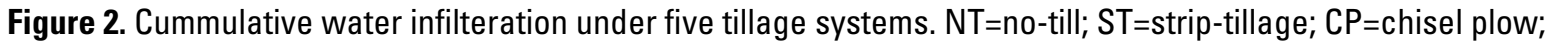
$\mathrm{DR}=$ deep rip; $\mathrm{MP}=$ moldboard plow.

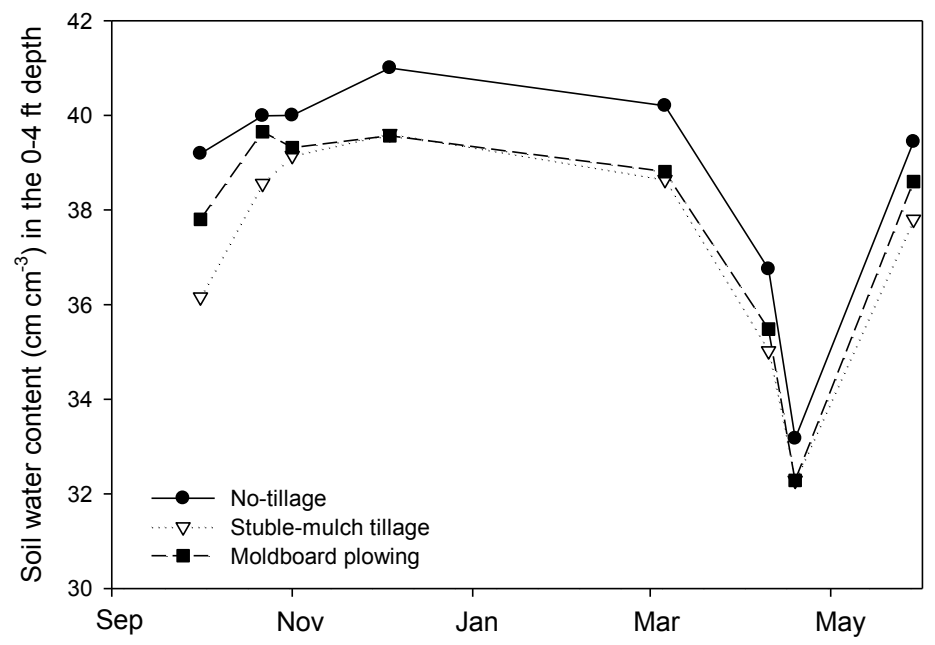

Figure 3. Tillage effects on soil water content between fall tillage and the start of next years the growing season, (Dao, 1993). 


\section{Residue management and cover crops under drought conditions}

Crop residues play significant role at several levels of soil sustainability. Primarily, crop residue physically protects the soil from potential erosion during heavy rain events. Crop residue reduces the impact of rain drops by absorbing the kinetic energy of rain drops to create a gentle infiltration and slow movement of water in the soil. Thus, reducing soil erosion and increasing the time opportunity for water to percolate the soil for better water recharge of the subsoil to save crop yield during drought. The effectiveness of residue in achieving these goals depends on how it is managed, which starts during harvest by cutting corn at a minimum height of 12 inches above the ground. The upright residue can be very effective in trapping soil moisture in term of snow and slow water movement (McMaster et al., 2000). Residue should be kept intact to increase its effeteness. Shredding or chopping residue can create a lot of problems in terms of its ability to reduce soil erosion and potential washout during high intensity rain events.

Post-harvest cover crops can be essential components of drought management to mitigate yield losses. The benefits of cover crops and crop residue include protecting the soil from excessive dryness to prevent cracks and fractures in the soil, thus improving soil water storage and soil microbial activity, nutrient cycling and uptake by plants (Aiken et al., 2003). Cover crops increase water storage by reducing evaporation and increasing water infiltration (Fig. 4).Cover crops take up water when they grow but prevent water losses from the soil surface. Reduction in evaporation from soil surfaces occur if the cover crop is left on the soil surface as mulch, but not if it is incorporated (Fig. 3). The best protection against moisture loss and wind erosion is a good protective cover of growing plants and plant residue.

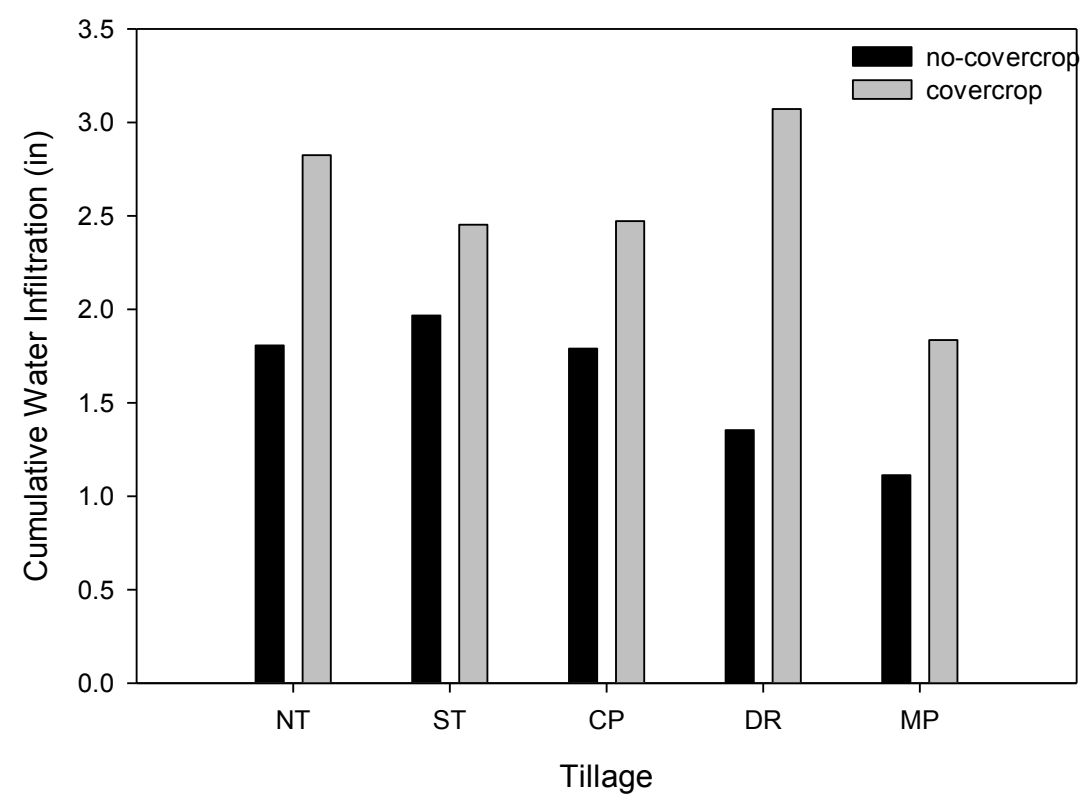

Figure 4. Tillage effects on cumulative water infiltration after 24 minutes of simulated rainfall. NT=no-till; $S T=$ striptillage; $\mathrm{CP}=$ chisel plow; $\mathrm{DR}=$ deep rip; $\mathrm{MP}=$ moldboard plow.

\section{Summary}

Drought results from lack of precipitation over an extended period. Soil conservation is essential to manage drought to sustain soil quality and improve crop productivity. No-till soils with stable soil structure and rich in organic matter promote water infiltration and increase soil water storage. With drought conditions, reducing tillage intensity as in ST or avoiding tillage as in NT can protect soil structure, increase soil water storage and reduce the effects of drought on corn yield. In the Southcentral region of Iowa where soils are high in clay content and poorly-drained, corn yields in 2012 were 30 and 5 bu/acre higher with NT and ST systems, respectively compared with corn yields with the same tillage systems in 2011. On the contrary, corn yields from tilled soils declined by 75 bu/acre in MP, 
$70 \mathrm{bu} / \mathrm{acre}$ in $\mathrm{CP}$ and $50 \mathrm{bu} / \mathrm{acre}$ in DR. In the Northcentral region with glacial till and poorly-draining soils and the Southwest region with loess and well-draining soils, corn yield reductions in 2012 across all tillage systems were in the range of 60-80 bu/acre and 58-73 bu/acre, respectively compared with 2011. The recent drought in Iowa led to early harvest. With the early harvest and extended period between harvest and the next growing season, farmers may be tempted to do more tillage at the risk of damaging the soil structure and subsequently damage the soil aggregate leading to soil surface sealing and a significant amount of runoff and soil erosion during rain events. Cover crops and crop residue are essential components of drought management to mitigate yield losses. Cover crops protect the soil from excessive dryness, prevent soil cracks and fractures, and improve, soil microbial activity, nutrient cycling and uptake by plants. Crop residue creates a slow but steady infiltration of water to increase the

time opportunity for water to move through the soil and recharge the sub soil that is essential for good yield during drought condition.

\section{References}

Aiken, R. M., Nielsen, D. C. and Ahuja, L. R. 2003. Scaling effects of standing crop residue on the wind profile. Agron J. 95: 1041-1046.

Celik, I and Ersahin, S. 2011. Evaluation of tillage influence on infiltration characteristics in a clay soil. J. Food, Agri. And Environ. 9(1):653-658.

Dao, T. H. 1993. Tillage and winter wheat residue management effects on water infiltration and storage. Soil Sci. Soc. Am. J. 57:1586-1595.

Green, T. R., Ahuja, L. R., Benjamin, J. G. 2003. Advances and challenges in predicting agricultural management effects on soil hydraulic properties. Geoderma 116: 3-27.

Kennedy, A. C. and Schillinger, W. F. 2006. Soil quality and water intake in traditional till vs. no-till paired farms in Washington's Palouse region. Soil Sci. Soc. Am. J. 70:940-949.

MacMaster, G. S., Aiken, R. M., and Nielsen, D. C. 2000. Optimizing wheat harvest cutting height for harvest efficiency and soil and water conservation. Agron J. 92:1104-1108.

Rippey, B. 2012. U. S. Drought Monitor. US Department of Agriculture. 